\title{
Orientation of OLED Emitter Molecules Revealed by XRD
}

\author{
Caroline Murawski ${ }^{1,2}$, Chris Elschner ${ }^{1}$, Simone Lenk ${ }^{1}$, Sebastian Reineke ${ }^{1}$, and Malte C. Gather ${ }^{1,2}$ \\ 1 Dresden Integrated Center for Applied Physics and Photonic Materials (IAPP) and Institute for Applied Physics, \\ Technische Universität Dresden, 01062 Dresden, Germany \\ 2 SUPA, School of Physics and Astronomy, University of St Andrews, North Haugh, St Andrews KY16 9SS, UK \\ Authore-mail address:cm337@st-andrews.ac.uk
}

\begin{abstract}
Thin films of the phosphorescent emitters $\operatorname{Ir}(\mathrm{ppy})_{3}$ and $\operatorname{Ir}(\mathrm{ppy})_{2}(\mathrm{acac})$ are investigated by GIXRD and GIWAXS. Both molecules form crystalline grains and exhibit a preferred orientation that is pertained even when doped into a host.

OCIS codes: (310.6860) Thin films, optical properties; (160.4890) Organic materials; (160.2540) Fluorescent and luminescent materials
\end{abstract}

\section{Introduction}

Orientation of emitting dipoles in organic light-emitting diodes (OLEDs) has raised a lot of interest in the OLED community due to its potential to strongly increase outcoupling efficiency [1-4]. Especially for perfectly horizontally oriented emitter dipoles, the efficiency may be increased by up to $60 \%$ compared to isotropic orientation due to the preferred emission of the transition dipoles into forward direction [5]. The orientation of various emitter molecules has been investigated and many compounds exhibiting a preferential horizontal orientation have been found. However, the origin of their preferred orientation is still under debate [5-7].

In this contribution, we investigate the orientation of the archetype phosphorescent emitters $\operatorname{Ir}(\text { ppy })_{3}$ and $\operatorname{Ir}(\mathrm{ppy})_{2}(\mathrm{acac})$ with respect to the substrate. Despite their structural similarity, it was previously found that the two emitters exhibit a different orientation of their transition dipole moments, where an isotropic orientation was found for $\operatorname{Ir}(\mathrm{ppy})_{3}$ and a preferential horizontal orientation for $\operatorname{Ir}(\mathrm{ppy})_{2}(\mathrm{acac})$ [3]. Using grazing incidence X-ray diffraction (GIXRD), we find that both emitters form crystallite grains that are pertained even when the emitter is doped into a host. Further investigations via 2D grazing incidence wide-angle X-ray scattering (GIWAXS) reveal that the crystallite grains of both emitters show a preferential orientation in out-of-plane direction.

\section{Experimental and results}

Thin films of either neat tris(2-phenylpyridine)iridium(III) (Ir(ppy) $)_{3}$ and bis(2-phenylpyridine) (acetylacetonate)iridium(III) $\left(\operatorname{Ir}(\mathrm{ppy})_{2}(\mathrm{acac})\right)$ or doped into the host 4,4',4"-tris(N-carbazolyl)-triphenylamine (TCTA) were fabricated by thermal evaporation in UHV (Kurt J. Lesker Co.) at a base pressure of $10^{-8}$ mbar onto pre-cleaned glass substrates. X-ray measurements were performed in air. For GIXRD, a Bruker D8 Discover diffractometer was used with $\mathrm{Cu}-\mathrm{K}_{\alpha}$ radiation $(\lambda=1.54 \AA)$ and the signal was detected with a scintillation counter. The incident angle was previously determined to be $\omega \approx 0.2^{\circ}$ while the angle $2 \theta$ is scanned from $3-90^{\circ}$ in $0.1^{\circ}$ steps at $30 \mathrm{~s}$ sampling time. All measurements were corrected for a background that was previously measured at smaller incident angle, where total reflection occurs between the interface of air and organic. 2D GIWAXS measurements were performed at the Stanford Synchrotron Radiation Lightsource (SSRL), beamline 11-3, at $12.735 \mathrm{keV}$ and scattered X-rays were detected with a 2D image plate. All GIWAXS data are isotropically converted to $q$-values ( $q$ denotes the scattering vector) and are further analysed using the software WxDiff [8].
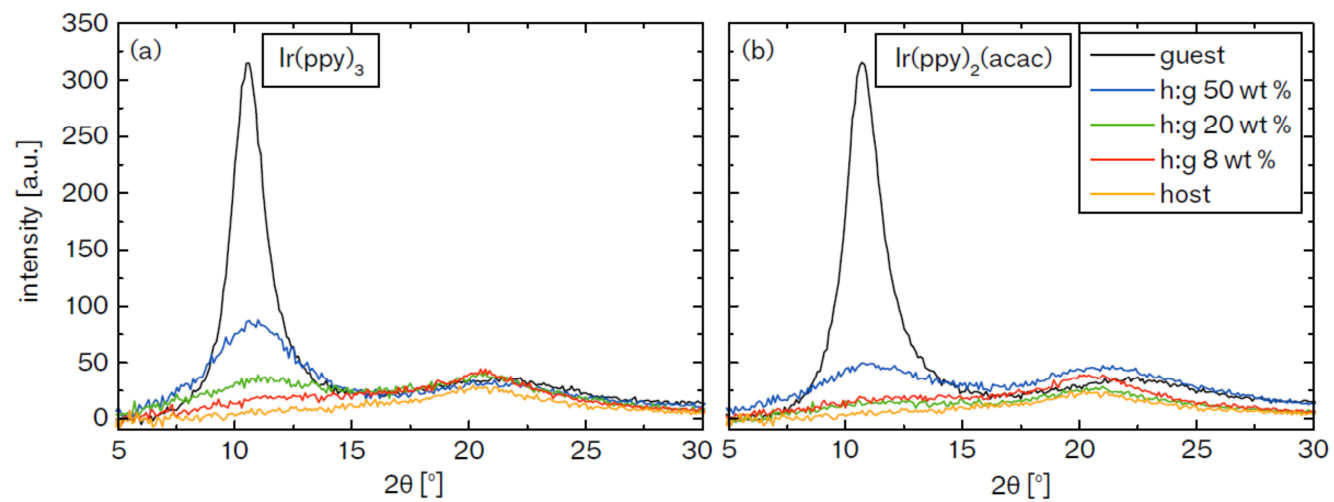

Fig. 1. Grazing incidence X-ray diffraction measurements on mixed films of a) $\operatorname{Ir}(\mathrm{ppy})_{3}$ and b) $\operatorname{Ir}(\mathrm{ppy})_{2}$ (acac) doped into the host TCTA at varying doping concentrations from neat emitter films to neat host film. A distinct peak in Bragg reflection is observed at approximately $11^{\circ}$. 
Figure 1 shows the GIXRD spectra for $50 \mathrm{~nm}$ thick neat $\operatorname{Ir}(\mathrm{ppy})_{3}, \operatorname{Ir}(\mathrm{ppy})_{2}(\mathrm{acac})$ and TCTA films as well as host:guest blends of 8, 20, and $50 \mathrm{wt} \%$. Neat emitter films show a strong Bragg reflection at approximately $11^{\circ}$. The peak significantly decreases when blending the emitter into TCTA but is still pertained at doping concentrations above $20 \mathrm{wt} \%$. At $8 \mathrm{wt} \%$, a concentration typically used in OLEDs, the peak cannot be detected anymore. TCTA, instead, shows no Bragg reflection and only a very broad signal around $22^{\circ}$, which originates from diffusely scattered radiation [9]. Hence, we conclude that TCTA is fully amorphous.

The Bragg reflection at $11^{\circ}$ indicates that both emitters form crystalline grains and that these grains are even pertained when the emitter is doped into the host. In order to quantify the grain size, we fitted the GIXRD spectra with two Gaussian functions in order to extract the exact position and FWHM of the Bragg reflection (cf. Fig. 2). From the peak position $2 \theta_{0}$ and the FWHM, the coherence length $L_{\mathrm{c}}$ can be calculated via the Scherrer equation [10]:

$$
L_{\mathrm{c}}=\frac{K \lambda}{\cos \left(\frac{2 \theta_{0}}{2}\right) \mathrm{FWHM}} .
$$

Here, $K$ denotes a shape factor that is set to 1 , while $\lambda$ is the wavelength of the X-rays. The resulting $L_{\mathrm{c}}$ and $2 \theta_{0}$ are summarized in Table 1. The Bragg reflections of $\operatorname{Ir}(\text { ppy })_{3}$ and $\operatorname{Ir}(\text { ppy })_{2}(\mathrm{acac})$ are located at $10.60^{\circ}$ and $10.82^{\circ}$, respectively. For both materials, the peak shifts slightly towards higher angles with decreasing doping concentration, which would indicate a compression of the grains in real space. The coherence length is larger for $\operatorname{Ir}(\mathrm{ppy})_{3}$ compared to $\operatorname{Ir}(\mathrm{ppy})_{2}(\mathrm{acac})$ at all investigated concentrations, which is supported by the well-known tendency of $\operatorname{Ir}(\mathrm{ppy})_{3}$ and, to a significantly lesser extent, $\operatorname{Ir}(\mathrm{ppy})_{2}$ (acac) to form aggregates [11]. The coherence length significantly decreases when doping the emitter into a matrix. In these investigations, the coherence length denotes the minimum size of an aggregate in out-of-plane direction (i.e. perpendicular to the substrate). Hence, aggregates may be much larger if the molecular structure is distorted due to disorder.

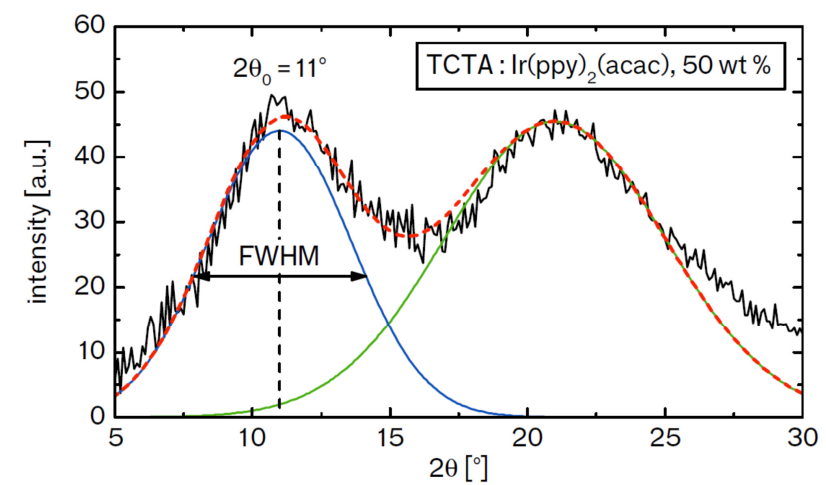

Fig. 2. GIXRD spectra are fitted with two Gaussian functions in order to reveal the peak position $2 \theta_{0}$ and FWHM of the Bragg reflection.

Table 1. Fitting parameters of Bragg reflections as obtained from GIXRD spectra of $\operatorname{Ir}(\mathrm{ppy})_{3}$ and $\operatorname{Ir}(\mathrm{ppy})_{2}(\mathrm{acac})$ and of emitter blends with TCTA. The peak position is given by $2 \theta_{0}$ and $L_{\mathrm{c}}$ denotes the coherence length as calculated with Eq. 1 .

\begin{tabular}{|c|c|c|c|c|}
\hline material & \multicolumn{2}{|c|}{$\operatorname{Ir}(\mathrm{ppy})_{3}$} & \multicolumn{2}{c|}{$\operatorname{Ir}(\mathrm{ppy})_{2}(\mathrm{acac})$} \\
\hline & $2 \theta_{0}\left[^{\circ}\right]$ & $L_{\mathrm{c}}[\mathrm{nm}]$ & $2 \theta_{0}\left[^{\circ}\right]$ & $L_{\mathrm{c}}[\mathrm{nm}]$ \\
\hline guest & $10.60 \pm 0.01$ & $4.38 \pm 0.04$ & $10.82 \pm 0.02$ & $3.81 \pm 0.07$ \\
\hline TCTA:guest 50 wt.\% & $10.75 \pm 0.02$ & $2.07 \pm 0.03$ & $10.99 \pm 0.06$ & $1.43 \pm 0.04$ \\
\hline TCTA:guest 20 wt.\% & $10.95 \pm 0.06$ & $1.49 \pm 0.04$ & $12.40 \pm 0.10$ & $1.24 \pm 0.05$ \\
\hline
\end{tabular}

GIXRD is a suitable method to investigate the structure in one direction, however, no conclusion on orientation can be drawn. In order to investigate how the observed crystallite grains are oriented with respect to the substrate, we performed 2D GIWAXS measurements on neat $\operatorname{Ir}(\mathrm{ppy})_{3}$ and $\operatorname{Ir}(\mathrm{ppy})_{2}(\mathrm{acac})$ films. Here, the crystal structure is not only imaged in one direction but into two directions, which enables differentiating between scattering structures in in-plane and in out-of-plane direction of the sample. Figure 3 shows the observed result. A strong peak is observed in out-of-plane direction at $q_{\mathrm{z}}=0.75 \AA^{-1}$, which resembles the Bragg peak at approximately $11^{\circ}$ observed in Fig. 1 . The intensity of this peak significantly decreases for lower polar angles $\chi$ (going from out-of-plane direction towards in-plane). This indicates that the crystallite grains are mainly oriented in out-of-plane direction. 

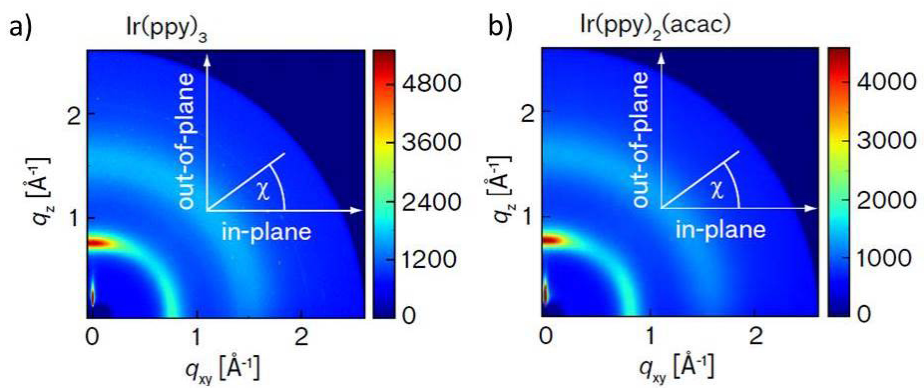

Fig. 3. Grazing incidence wide-angle X-ray scattering data of a) neat $\operatorname{Ir}(\mathrm{ppy})_{3}$ and b) neat $\operatorname{Ir}(\mathrm{ppy})_{2}(\mathrm{acac})$ films. $q_{\mathrm{z}}$ denotes the out-of-plane direction and $q_{\mathrm{xy}}$ the in-plane direction. A distinct peak is observed in out-of-plane direction indicating a preferential orientation of molecules.

Finally, we will compare the observed orientation of the crystallite grains to the orientation of emitting dipoles. For $\operatorname{Ir}(\text { ppy })_{3}$, the observed Bragg reflection most probably originates from the (220)-plane [12]. Here, we found that the diffraction pattern of this plane is mainly oriented in out-of-plane direction, which means that the planes lie roughly parallel to the substrate. Within the planes, $\operatorname{Ir}(\mathrm{ppy})_{3}$ molecules are oriented with their symmetry axis roughly parallel to $c$ [12], hence, also roughly parallel to the substrate. The final question is how the transition dipole moments are oriented with respect to the symmetry axis of the molecule. Recently, it was found that the dipole moments of the three triplet sublevels of $\operatorname{Ir}(\text { ppy })_{3}$ point towards the three ligands and are mutually orthogonal [13]. Hence, even if the $\operatorname{Ir}(\text { ppy })_{3}$ molecules are oriented parallel to the substrate, their transition dipole moments cancel each other out. Unfortunately, to the best of our knowledge, the crystal structure and orientation of the transition dipole moments of $\operatorname{Ir}(\mathrm{ppy})_{2}$ (acac) have not been reported so far.

\section{Conclusions}

Using X-ray diffraction techniques, we studied the orientation and molecular structure of $\operatorname{Ir}(\text { ppy })_{3}$ and $\operatorname{Ir}(\text { ppy })_{2}($ acac $)$ films. We found that both molecules exhibit a preferential orientation on the substrate and could explain how this orientation compares to the observed isotropic orientation of the transition dipole moments in the case of $\operatorname{Ir}(\text { ppy })_{3}$. Interestingly, for the materials studied here the orientation of the emitters seems to be an intrinsic property of the film and is not governed by its environment, i.e. the host material, as previously suggested in literature [5].

\section{Acknowledgment}

We thank Dr. Lutz Wilde at Fraunhofer IPMS, Center Nanoelectronic Technologies, Dresden for carrying out the GIXRD measurements. CM acknowledges funding by the Graduate Academy of the TU Dresden and by the European Commission through a Marie Skłodowska Curie individual fellowship (703387).

\section{References}

1. T. D. Schmidt, D. S. Setz, M. Flämmich, J. Frischeisen, D. Michaelis, B. C. Krummacher, N. Danz, and W. Brütting, "Evidence for non-isotropic emitter orientation in a red phosphorescent organic light-emitting diode and its implications for determining the emitter's radiative quantum efficiency," Appl. Phys. Lett. 99, 163302 (2011).

2. M. Flämmich, J. Frischeisen, D. S. Setz, D. Michaelis, B. C. Krummacher, T. D. Schmidt, W. Brütting, and N. Danz, "Oriented phosphorescent emitters boost OLED efficiency," Org. Electron. 12, 1663-1668 (2011).

3. P. Liehm, C. Murawski, M. Furno, B. Lüssem, K. Leo, and M. C. Gather, "Comparing the emissive dipole orientation of two similar phosphorescent green emitter molecules in highly efficient organic light-emitting diodes," Appl. Phys. Lett. 101, 253304 (2012).

4. D. Yokoyama, "Molecular orientation in small-molecule organic light-emitting diodes," J. Mater. Chem. 21, 19187 (2011).

5. K.-H. Kim, S. Lee, C.-K. Moon, S.-Y. Kim, Y.-S. Park, J.-H. Lee, J. W. Lee, J. Huh, Y. You, and J.-J. Kim, "Phosphorescent dye-based supramolecules for high-efficiency organic light-emitting diodes," Nat. Commun. 5, 4769 (2014).

6. A. Graf, P. Liehm, C. Murawski, S. Hofmann, K. Leo, and M. C. Gather, "Correlating the transition dipole moment orientation of phosphorescent emitter molecules in OLEDs with basic material properties," J. Mater. Chem. C 2, 10298 (2014).

7. M. J. Jurow, C. Mayr, T. D. Schmidt, T. Lampe, P. I. Djurovich, W. Brütting, and M. E. Thompson, "Understanding and predicting the orientation of heteroleptic phosphors in organic light-emitting materials," Nat. Mater. (2015).

8. S. C. B. Mannsfeld, M. L. Tang, and Z. Bao, "Thin film structure of triisopropylsilylethynyl-functionalized pentacene and tetraceno[2,3-b]thiophene from grazing incidence x-ray diffraction," Adv. Mater. 23, 127 (2011).

9. C. Elschner, "Structural Investigations of Disordered Organic Thin Films," PhD thesis, Technische Universität Dresden (2013).

10. J. Rivnay, S. C. B. Mannsfeld, C. E. Miller, A. Salleo, and M. F. Toney, "Determination of Organic Semiconductor Microstructure from the Molecular to Device Scale," Chem. Rev. 112, 5488 (2012).

11. S. Reineke, T. C. Rosenow, B. Lüssem, and K. Leo, "Improved High-Brightness Efficiency of Phosphorescent Organic LEDs Comprising Emitter Molecules with Small Permanent Dipole Moments.," Adv. Mater. 22, 3189 (2010).

12. R. J. F. Berger, H. G. Stammler, B. Neumann, and N. W. Mitzel, "Fac-Ir(ppy)3: Structures in the gas-phase and of a new solid modification," Eur. J. Inorg. Chem. 2010, 1613-1617 (2010).

13. C.-K. Moon, K.-H. Kim, J. W. Lee, and J.-J. Kim, "Influence of Host Molecules on Emitting Dipole Orientation of Phosphorescent Iridium Complexes," Chem. Mater. 27, 2767-2769 (2015). 